\title{
Effects of Particle Sizes on Sintering Behavior of 316L Stainless Steel Powder
}

\author{
DONG YONG PARK, SHI W. LEE, SEONG JIN PARK, YOUNG-SAM KWON, \\ and ISAMU OTSUKA
}

\begin{abstract}
In rapidly evolving powder injection molding technology, the wide prevalence of various microstructures demands the powders of smaller particle sizes. The effects of particle size on the sintering behavior are critical to not only shape retention of microstructure but also its mechanical properties. This study investigates the effects of three different particle sizes on the sintering behavior of the $316 \mathrm{~L}$ stainless steel (STS316L) samples, prepared by powder injection molding, via the dilatometry experiments. For this purpose, the STS316L powders of three different mean particle sizes, i.e., 2.97, 4.16, and $8.04 \mu \mathrm{m}$, were produced for STS316L. The samples for the dilatometry test were prepared through powder-binder mixing, injection molding, and solvent and thermal debinding. Dilatometry experiments were carried out with the samples in a $\mathrm{H}_{2}$ atmosphere at three different heating rates of 3,6 , and $10 \mathrm{~K} / \mathrm{min}$. The shrinkage data obtained by dilatometry experiments was collected and analyzed to help understand the densification and the sintering behaviors in terms of particles size and heating rate. The master sintering curve (MSC) model was used to quantify the effects of particle sizes. In addition, we investigated the microstructure evolutions in terms of particles sizes.
\end{abstract}

DOI: $10.1007 / \mathrm{s} 11661-012-1477-\mathrm{x}$

(C) The Minerals, Metals \& Materials Society and ASM International 2012

\section{INTRODUCTION}

As more than half of injection-molded and sintered components are made of stainless steel powders nowadays, understanding the densification behaviors of stainless steel powders is of great importance and interest to successful sintering processes. ${ }^{[1-3]}$ Among various stainless steels, 316L stainless steel has excellent mechanical properties of high corrosion resistance, high heat resistance, and good weldability. In this regard, 316L stainless steel is one of the most widely used materials for powder injection molding (PIM) research and industrial applications such as pharmaceuticals, architectural applications, and medical implants including pins, screws, and orthopedic implants such as hip and knee replacements.

In manufacturing industries, the PIM process is a productive and cost-effective net-shaping process, which combines advantages of both plastic injection molding and conventional powder metallurgy. This process has many advantages including shape complexity, tight tolerances, and material selection of metals and ceramics. Once desired materials, mold geometries, and

DONG YONG PARK, Graduate Student, Department of Mechanical Engineering, and SEONG JIN PARK, Associate Professor, Department of Mechanical Engineering and Division of Advanced Nuclear Engineering, are with POSTECH, Pohang, Gyungbuk 790-784, Korea. SHI W. LEE, Assistant Professor, is with the Department of Industrial Engineering, Pusan National University, Busan 609-735, Korea. YOUNG-SAM KWON, President, is with CetaTech, Inc., Sacheon, Gyungnam 664-950, Korea. ISAMU OTSUKA, Director, is with the MP Development \& Engineering Department, Epson Atmix Corporation, Hachinohe, Aomori 039-1161,

Japan. Contact e-mail: sjpark87@postech.ac.kr

Manuscript submitted February 22, 2012.

Article published online November 8, 2012 process parameters are decided, PIM is an appropriate process for the mass production.

The PIM process consists of four steps: (1) mixingproducing the pelletized feedstock of the powder and organic binders; (2) molding - injecting the feedstock melt into the mold cavity, similar with thermoplastics; (3) debinding - extracting or removing the organic binders out of the injection-molded part via solvents or the thermal energy; and (4) sintering - densifying the debound part from the low initial density to the high final density, close to the full density. ${ }^{[4]}$ Figure 1 shows a schematic diagram of the PIM process.

Sintering, a thermally activated diffusion process, is one of the key steps in the PIM process as well as other powder metallurgy processes, which affects the density as well as other mechanical properties of the final part. Among several mechanical properties that are affected by sintering, the density can be said to be one of the most important factors to evaluate merchantability of sintered parts. The density of sintered parts is related to final dimensions as well as hardness of the part, since the pores occupying a significant portion in volume are eliminated and individual particles are bonded together into a coherent, solid mass during the high-temperature sintering. ${ }^{[1]}$ Hence, understanding the densification behaviors of molded parts during the sintering process is critical to management of the dimensions and hardness of sintered parts. However, it has been known to be difficult to predict how the densification takes place during the sintering process since sintering is a complicated process affected by many factors including size distribution and morphology of particles, heating profile, and sintering atmosphere. In this regard, a careful prediction of densification behaviors plays an 


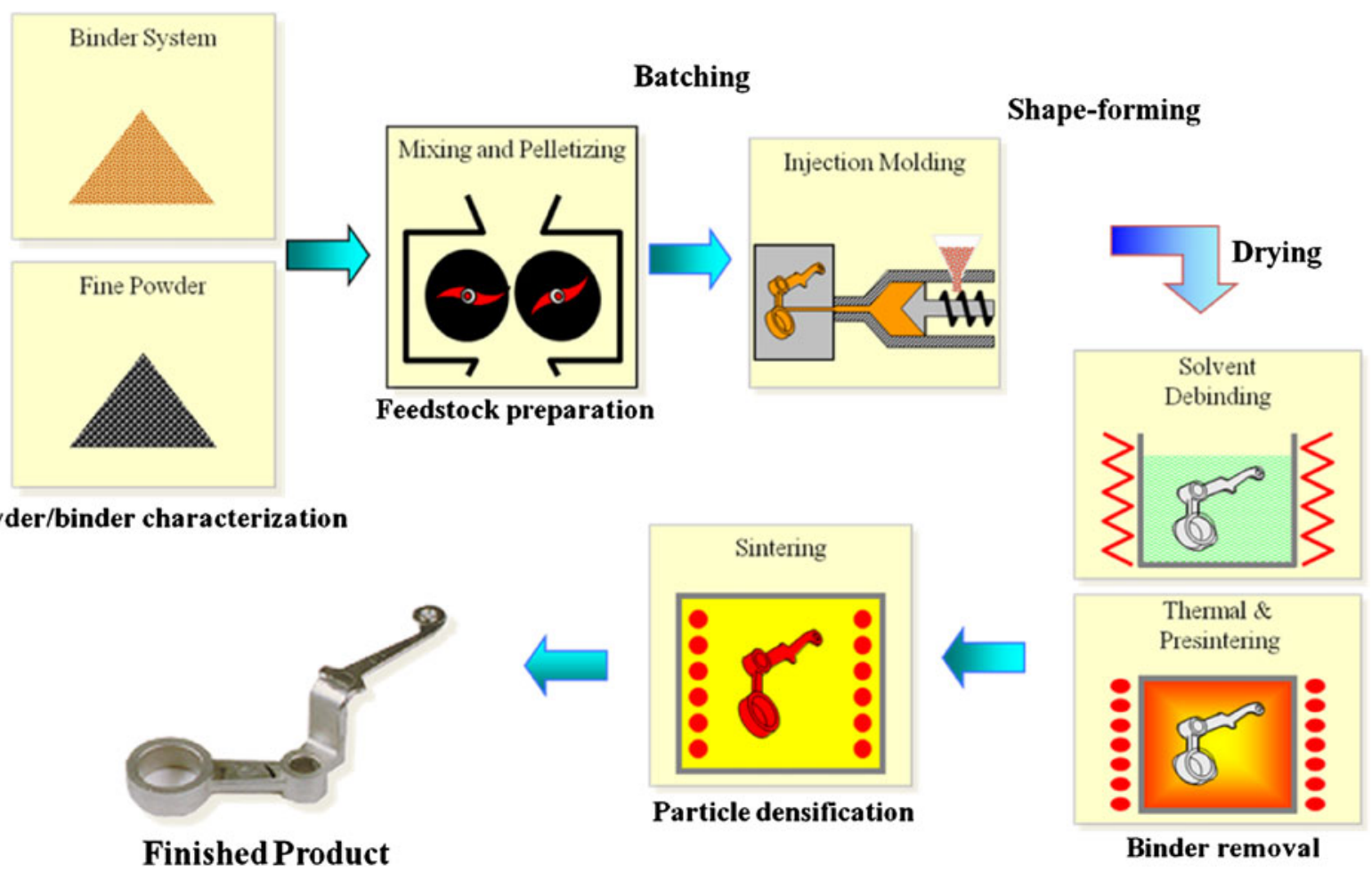

Fig. 1-Schematic diagram of powder injection molding.

important role not only in shape retention of the final part, but also in mechanical and engineering properties.

Most research has classified the sintering process into three stages: initial, intermediate, and final. It has focused on individual stages as well as the combined stages. Several attempts were made to predict and simulate the sintering behavior in the past. Hassold and Chen, ${ }^{[5]}$ and Coble, ${ }^{[6]}$ used Monte-Carlo methods to predict the densification behavior in the final stage of sintering process. Another simulation effort using the continuum theory was made by Reid. ${ }^{[7]}$ His model requires the surface energy to simulate the sintering behavior. Among various analysis models, the master sintering curve (MSC) model, which was developed by Su and Johnson, ${ }^{[8]}$ has been widely adopted by many other researchers to explain sintering behavior in a full range. They suggested that the densification behavior can be predicted using a minimal set of preliminary experiments regardless of heating profiles by formulating and constructing the MSC. Their theory has been applied to predict the sintering behavior ${ }^{[3,9-18]}$ in many other's research.

In this study, the MSC model suggested by $\mathrm{Su}$ and Johnson was used to characterize the effects of particle sizes in injection-molded parts on sintering behaviors. The MSC, derived from the combined-stage sintering model $\left[{ }^{[19]}\right.$ explains the relationship between the sintered density, $\rho$, and the thermal history during sintering, i.e., the sintering time, $t$, and temperature, $T$.

The increasing demand for the microstructured part requires the powders of smaller sizes than before. Hence, several attempts to use small particles were reported. ${ }^{[4]}$ Okubo et al. ${ }^{[20]}$ used three different particle sizes $(8.5,9.8$ and $11.2 \mu \mathrm{m}$ for STS316L and 3, 4.6, and $9.6 \mu \mathrm{m}$ for
STS17-4PH) to understand the effects of particle sizes and distribution on dimensional accuracy. They analyzed the relationship between sintered densities and particle sizes. Liu et al ${ }^{[21]}$ investigated the final-stage sintering of various microsized structures. In their study, the effects of size reduction of various microsize structures were investigated using mean particle size $2.37 \mu \mathrm{m}$. The size of 100 - and $60-$ $\mu \mathrm{m}$ microcomponents were fabricated with good shape replication using $2.37 \mu \mathrm{m}$. Robertson and Schaffer ${ }^{[9]}$ investigated the effects of particle sizes on sintering behaviors using titanium powders of 5 to $500 \mu \mathrm{m}$.

This study investigates the effects of particle sizes on the sintering behavior using MSC. As explained previously, the material, the particle sizes, and morphology vary the apparent activation energies. Section II presents the preliminary backgrounds in MSC and its sigmoid function representation. Furthermore, a way to obtain the apparent activation energy, originally proposed by Park and German ${ }^{[13]}$ will be briefly explained. In Section III, the experimental procedure and characterization data of powders, which are used in this study, will be presented. Section IV describes the procedure of data collection from the dilatometry experiments. The MSC analysis for the data that were obtained in this study is described, and its results are given in Section V. Finally, the conclusions and contributions of this study are presented in Section VI.

\section{PRELIMINARY BACKGROUNDS IN MSCS}

\section{A. Combined-Stage Sintering Model}

The preliminary theory of the MSC model is described in this section. The MSC model was derived 
from the instantaneous linear shrinkage rate in the combined-stage sintering mode ${ }^{[8]}$ :

$$
-\frac{d L}{L d t}=\frac{\gamma \Omega}{\mathrm{k} T}\left[\frac{\Gamma_{V} D_{V}}{G^{3}}+\frac{\Gamma_{\mathrm{b}} \delta D_{\mathrm{b}}}{G^{4}}\right]
$$

where $\gamma$ is the surface energy, $\Omega$ is the atomic volume, $\mathrm{k}$ is the Boltzmann constant, $T$ is the absolute temperature, $\delta$ is the width of the grain boundary, $G$ is the mean grain diameter, $D_{V}$ and $D_{\mathrm{b}}$ are the coefficients for volume and grain boundary diffusion, and $\Gamma$ is the lumped scaling parameter. In order to predict the sintering behavior, the MSC model is derived from the confined segments of linear shrinkage rate. The MSC curve is constructed by integrating confined segments of linear shrinkage over the full stage of sintering process.

For isotropic shrinkage, the shrinkage rate and the densification rate have the following relationship:

$$
-\frac{d L}{L d t}=\frac{d \rho}{3 \rho d t}
$$

where $\rho$ is the relative density and $L$ is the length of the sample. By substituting Eq. [1] into Eq. [2], one obtains the following equation:

$$
\frac{d \rho}{3 \rho d t}=\frac{\gamma \Omega}{\mathrm{k} T}\left[\frac{\Gamma_{V} D_{V}}{G^{3}}+\frac{\Gamma_{\mathrm{b}} \delta D_{\mathrm{b}}}{G^{4}}\right]
$$

Assuming that sintering behaviors depend only on a single dominant diffusion mechanism (either volume diffusion or grain-boundary diffusion), Eq. [3] can be simplified to the following equation ${ }^{[8,19,22]}$.

$$
\frac{d \rho}{3 \rho d t}=\frac{\gamma \Omega(\Gamma(\rho)) D_{0}}{\mathrm{k} T(G(\rho))^{n}} \exp \left(-\frac{Q}{\mathrm{R} T}\right)
$$

where $Q$ is the apparent activation energy; $\mathrm{R}$ is the gas constant; and $D_{0}=\left(D_{\mathrm{v}}\right)_{0}$ and $D_{0}=\left(\delta D_{\mathrm{b}}\right)_{0}$ are the preexponential coefficients of the volume diffusion coefficient for $n=3$ and pre-exponential coefficient of grain boundary diffusion coefficient for $n=4$, respectively. It is assumed that $G$ and $\Gamma$ values are the functions of density. Although there has been much effort to measure the lumped scaling parameter $(\Gamma)$ experimentally, it was a quite complicated task to determine the exact value of $\Gamma$, because $\Gamma$ depends on various parameters including the density and several geometric terms. To overcome this difficulty, $\mathrm{Su}$ and Johnson suggested the separation of density-dependent and process-related parameters, leading to the following model (Eq. [5]):

$$
\int_{\rho_{0}}^{\rho} \frac{k G^{n}}{3 \gamma \Omega \rho D_{0} \Gamma} d \rho=\int_{t_{0}}^{t} \frac{1}{T} \exp \left(-\frac{Q}{\mathrm{R} T}\right) d t
$$

On the left-hand side of Eq. [5], the parameters affected by the relative density are grouped together, while all process-related parameters are grouped together on the right-hand side. $Q$ is the apparent activation energy, which is usually found empirically from constant heating rate experiments. ${ }^{[10]}$
The left-hand side of Eq. [5] is defined as follows:

$$
\Pi(\rho) \equiv \int_{\rho_{0}}^{\rho} \frac{k G^{n}}{3 \gamma \Omega \rho D_{0} \Gamma} d \rho
$$

which includes parameters of microstructural and materials properties. The right-hand side of Eq. [5] is commonly referred to as a work of sintering $(\Theta)$ :

$$
\Theta(t, T)=\int_{t_{0}}^{t} \frac{1}{T} \exp \left(-\frac{Q}{\mathrm{R} T}\right) d t
$$

Equation [6] explains the effects of the microstructural evolution on the sintering kinetics as densification occurs. The MSC is defined as a relationship between $\rho$ and $\Phi$. As previously mentioned, it is a complicated task to obtain the lumped scaling factor $(\Gamma)$. Therefore, another way to calculate $\Phi(\rho)$ is to calculate $\Theta(t, \mathrm{~T})$, the work of sintering until the density $\rho$ is achieved through the heating history in the duration $(0, t)$. A numerical approach to calculate the work of sintering in Eq. [7] is given in Section II-B.

\section{B. Construction of $M S C s$}

The apparent activation energy has to be determined to calculate the work of sintering and to obtain the MSC. Various methods exist to determine the activation energy. In this study, a normalized dimensionless mean residual square is used to determine the apparent activation energy. From the shrinkage data obtained by dilatometry experiments, the following numerical procedures are carried out to find the apparent activation energy that minimizes the mean residual in Eq. [8].

$$
\text { Mean Residual }=\sqrt{\frac{1}{\rho_{f}-\rho_{0}} \int_{\rho_{0}}^{\rho_{f}} \frac{\sum_{i=1}^{N}\left(\frac{\Theta_{\rho, i}}{\Theta_{\rho}}-1\right)^{2}}{N} d \rho}
$$

where $\rho_{0}$ is the initial relative density, $\rho_{f}$ is the final relative density, $N$ is the total number of dilatometry experiments, $\Theta_{\rho, I}$ is the work of sintering up to the density $\rho$ of the $i$ th dilatometry experiment, and $\bar{\Theta}_{\rho}$ is the average work of sintering up to the density $\rho$ for all experiments. The range of values for $\Theta$, over the duration of the sintering experiment (i.e., from $\Theta_{0}$ to $\Theta_{f}$ ), is wide because of the exponential function in its definition. This makes the integration with respect to $\Theta$ difficult. However, by changing the integral variable to the relative density, $\rho$, the integration can be elegantly simplified.

Given a value of $Q$, a value of mean residual in Eq. [8] is determined. It is natural that the best estimator of $Q$ would minimize the deviation, which is represented by the mean residual. Therefore, the apparent activation energy can be determined from the plot of the mean residuals against the values of $Q$, which minimizes the mean residual. 
$\mathrm{Su}$ and Johnson ${ }^{[8]}$ proposed the MSC as a form of sigmoid function, which relates the relative density with the work of sintering, as given in Eq. [9]:

$$
\rho=\rho_{0}+\frac{1-\rho_{0}}{1+\exp \left[-\frac{\ln \Theta-a}{b}\right]}
$$

where $\rho$ is the relative density, $\rho_{0}$ is the initial relative density, and both $a$ and $b$ are parameters of the sigmoid function. To obtain parameters $a$ and $b$, a linearization suggested by Blaine et al. ${ }^{[15]}$ was conducted and gives the following equations:

$$
a \equiv \ln \Theta_{\text {ref }}
$$

and

$$
b \equiv 1 / n
$$

where $\Theta_{\text {ref }}$ is the work of sintering halfway through densification, i.e., up to density $\rho=\left(\rho_{0}+1\right) / 2$, and $n$ is a power law exponent. The quantity $\Theta_{\text {ref }}$ is obtained from the experimental data and means the halfway point between initial density and final density during sintering.

\section{EXPERIMENTS}

The water-atomized stainless steel (SS) powders of 316L of three different mean particle sizes are used for the experiments. Epson Atmix Corporation (Aomoriken, Japan) provided SS powders of PF-3F, PF-5F, and PF-15F, which have the mean particle sizes of $2.97,4.16$, and $8.04 \mu \mathrm{m}$, respectively. The morphology of the powders is irregular in shape for all three powders. The particle characterization data for STS316L powders are given in Table I. The chemical compositions of STS316L are summarized in Table II. The morphology of powders was observed using scanning electron microscopy (SEM), as shown in Figure 2.

The wax-polymer binder system, which consists of wax (57 pct), polypropylene (PP, $25 \mathrm{pct}$ ), polyethylene (PE, $15 \mathrm{pct}$ ), and stearic acid (SA, 3 pct), was used to help the flow of the powders during the injection molding process and the retention of the shape of the green part. Physical properties of ingredients are given in Table III. The feedstock was prepared by using twin screw extruder type mixer at 59 pct solid loading by volume.

All samples for dilatometry experiments are prepared by powder injection molding using the feedstock under consideration. They are all cylinders with a height of around $8 \mathrm{~mm}$ and a diameter of around $3 \mathrm{~mm}$. The injection-molded samples are debound at $333 \mathrm{~K}$ for 10 hours in an N-Hexane solution. During the solvent debinding, some ingredients of wax-polymer binder of the injection-molded samples are dissolved, since the wax-polymer binder has a wide range of melting temperatures. Then, all samples are thermally debound and presintered via following thermal cycles; temperature was increased by ramping from $303 \mathrm{~K}$ to $1173 \mathrm{~K}$ $\left(30{ }^{\circ} \mathrm{C}\right.$ to $900{ }^{\circ} \mathrm{C}$ ) at $2 \mathrm{~K} / \mathrm{min}$ with intermediate 2-hour holds at $523 \mathrm{~K}, 723 \mathrm{~K}$, and $973 \mathrm{~K}\left(250{ }^{\circ} \mathrm{C}, 450{ }^{\circ} \mathrm{C}\right.$, and $700{ }^{\circ} \mathrm{C}$ ) using the tube furnace. During thermal debinding, the remaining wax-polymer binder ingredients having higher melting temperatures are removed. For reference, the heating rate of $2 \mathrm{~K} / \mathrm{min}$ is relatively low so that the weeping of the sample can be avoided.

The shrinkage of samples is observed and measured at given thermal cycles using a horizontal pushrod dilatometer (DIL 402C, Netzsch, Selb, Germany) in a hydrogen atmosphere. All debound samples undergo the following thermal cycle: (1) in the first step, all samples are heated at the identical heating rate of $10 \mathrm{~K} / \mathrm{min}$ from $303 \mathrm{~K}$ to $1173 \mathrm{~K}\left(30{ }^{\circ} \mathrm{C}\right.$ to $\left.900{ }^{\circ} \mathrm{C}\right)$; (2) in the second step, each sample is heated at different heating rates of 3,6 , and $10 \mathrm{~K} / \mathrm{min}$ from $1173 \mathrm{~K}$ to $1623 \mathrm{~K}\left(900{ }^{\circ} \mathrm{C}\right.$ to $\left.1350{ }^{\circ} \mathrm{C}\right)$, respectively; and (3) in the last step, all samples are cooled by natural convection to room temperature. For each particle size, three different experiments (that is, three different heating rates of 3,6 , and $10 \mathrm{~K} / \mathrm{min}$ in the second step) are carried out, as shown in Figure 3. Theoretically, the shrinkages of samples are equivalent regardless of the heating profiles during sintering.

Table I. Particle Characteristics of STS316L Powders

\begin{tabular}{lcccccc}
\hline & \multicolumn{3}{c}{ Mean Diameter $(\mu \mathrm{m})$} & & & \\
\cline { 2 - 4 } Powder & $D_{10}$ & $D_{50}$ & $D_{90}$ & Apparent Density $\left(\mathrm{g} / \mathrm{cm}^{3}\right)$ & Tap Density $\left(\mathrm{g} / \mathrm{cm}^{3}\right)$ & Pycnometer Density $\left(\mathrm{g} / \mathrm{cm}^{3}\right)$ \\
\hline PF-3F & 1.62 & 2.97 & 4.85 & 2.28 & 4.04 & 7.91 \\
PF-5F & 2.10 & 4.16 & 7.64 & 2.44 & 4.21 & 7.94 \\
PF-15F & 3.01 & 8.04 & 19.94 & 3.24 & 4.41 & 7.94 \\
\hline
\end{tabular}

Table II. Chemical Composition of STS316L Powders

\begin{tabular}{llcccccccc}
\hline & \multicolumn{10}{c}{ Chemical Composition (Weight Percent) } \\
\cline { 2 - 9 } Powder & \multicolumn{1}{c}{$\mathrm{C}$} & $\mathrm{Si}$ & $\mathrm{Mn}$ & $\mathrm{P}$ & $\mathrm{S}$ & $\mathrm{Ni}$ & $\mathrm{Cr}$ & $\mathrm{Mo}$ & $\mathrm{Fe}$ \\
\hline PF-3F & 0.025 & 0.35 & 0.11 & 0.016 & 0.005 & 12.33 & 17.93 & 2.09 & bal \\
PF-5F & 0.26 & 0.35 & 0.09 & 0.013 & 0.004 & 12.14 & 17.66 & 2.08 & bal \\
PF-15F & 0.030 & 0.80 & 0.76 & 0.014 & 0.010 & 12.59 & 16.37 & 2.09 & bal \\
\hline
\end{tabular}




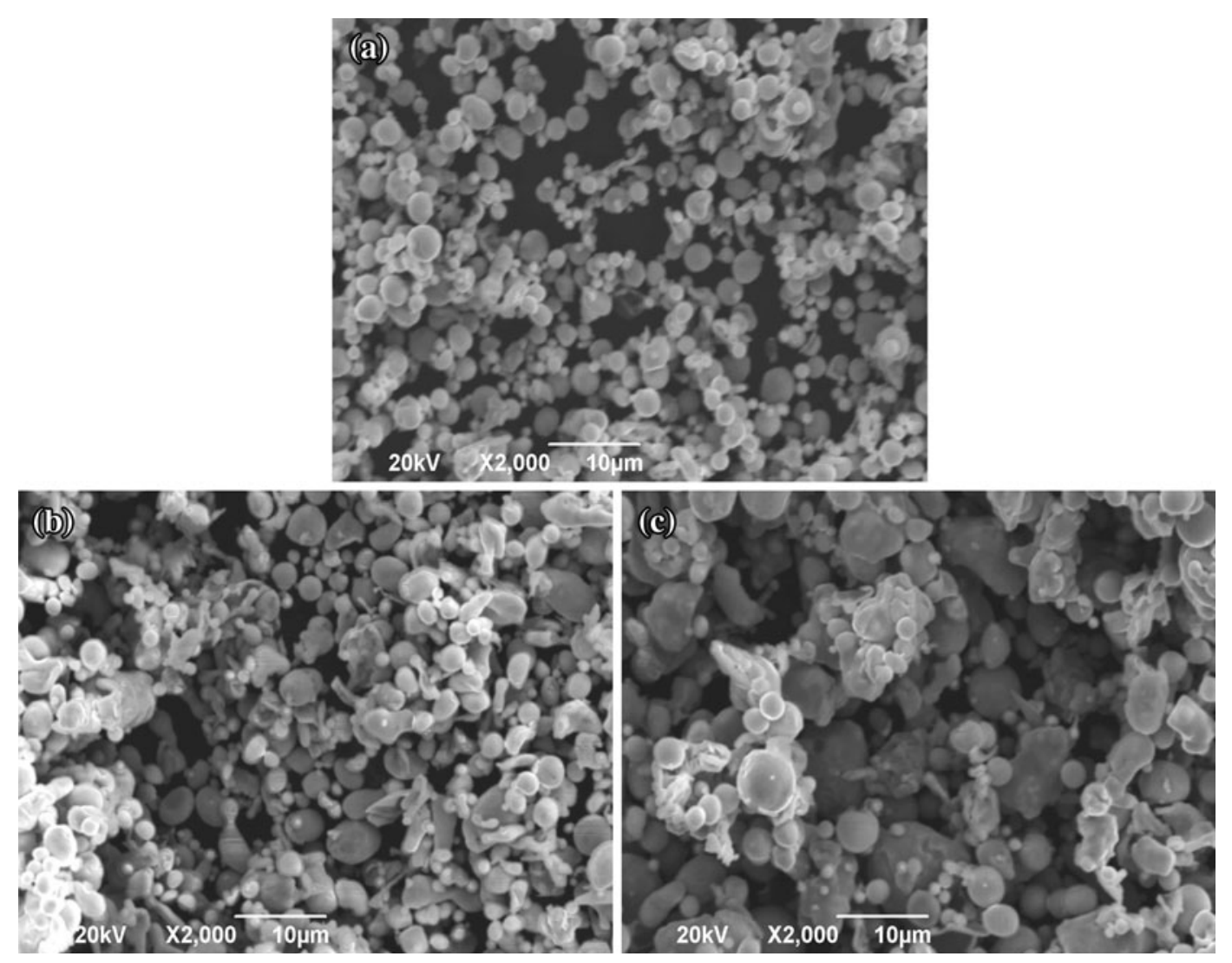

Fig. 2-Scanning electron micrographs of water-atomized 316L stainless steel powders: (a) PF-3F, (b) PF-5F, and (c) PF-15F.

Table III. Material Properties of Binder Ingredients

\begin{tabular}{lllll}
\hline Property & \multicolumn{1}{c}{ Wax } & \multicolumn{1}{c}{ PP } & PE & \multicolumn{1}{c}{ SA } \\
\hline Density $\left(\mathrm{g} / \mathrm{cm}^{3}\right)$ & 0.90 & 0.90 & 0.92 & 0.94 \\
Melting $(\mathrm{K})$ & 315 to 335 & 383 to 423 & 333 to 403 & 347 to 356 \\
Decomposition temperature $(\mathrm{K})$ & 453 to 593 & 623 to 743 & 693 to 753 & 536 to 579 \\
\hline
\end{tabular}

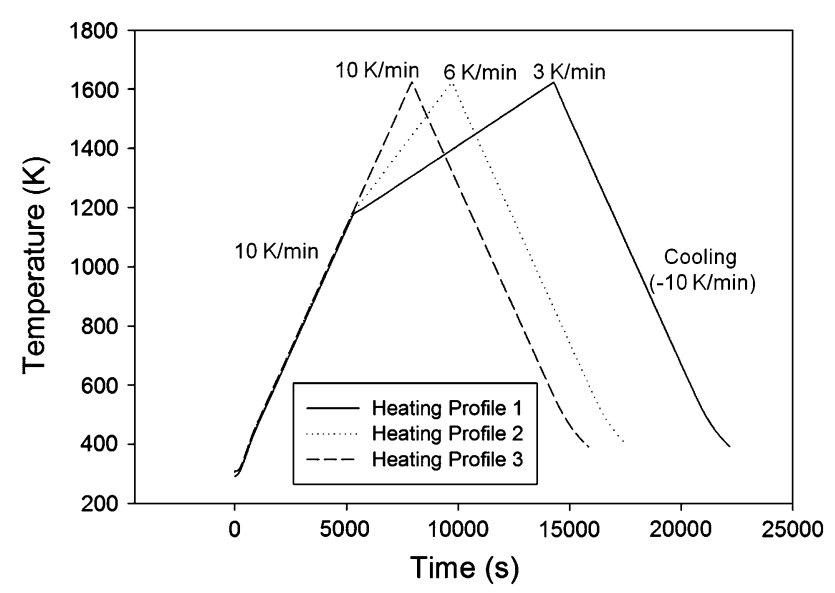

Fig. 3- Sinter cycles of dilatometry experiments for STS316L.

\section{TREATMENT OF DILATOMETRY DATA}

In order to construct the MSCs, the work of sintering $(\Theta)$ needs to be calculated from the dilatometry data (Eq. [7]). The dilatometry data include pairs of the specimen length $L$ and the corresponding temperature $T$. The treatment of dilatometry data was performed according to Blaine et al. ${ }^{[10]}$ At each temperature, the engineering strain is calculated by $\varepsilon_{d}=\left(L-L_{0}\right) / L_{0}$, where $L_{0}$ is the initial specimen length. If necessary, a normalization can be applied since the push rod of the dilatometer is being thermally expanded on the contrary to the sample. Then, the thermal expansion coefficient $\left(\alpha_{m}\right)$ is obtained from the cooling data of the dilatometry experiment by $\alpha_{m}=d \varepsilon_{d} / d T$. To compensate the thermal expansion effects, the (normalized) engineering strain $\varepsilon_{d}^{\prime}$ is corrected by $\varepsilon_{d}^{\prime}=\varepsilon_{d}-\alpha_{m} \rho^{1 / 3}\left(T-T_{0}\right)$, where $T_{0}$ is the 
initial room temperature. The relative density is obtained by $\rho=\rho_{0} /\left(1+\varepsilon^{\prime \prime} d\right)^{3}$ and can be corrected since the relative density is a monotonically increasing function to the temperature and the maximum density can be 1 .

The procedure described in this section generates the sintered relative density from the strain, assuming an isotropic shrinkage during sintering, in which the sample densifies from the initial relative density $\rho_{0}$ to the sintered relative density $\rho$ as follows;

$$
\rho=\rho_{0}\left(\frac{1}{1-d L / L_{0}}\right)^{3}
$$

\section{EXPERIMENTAL RESULTS AND DISCUSSION}

In order to predict densification behaviors for the powders of various sizes, dilatometry experiments were conducted and a systematic treatment of experimental data was carried out. In this section, experimental results and a treatment procedure of those data are explained. The results are analyzed in many respects, including shrinkages, strain rates, densification parameters, and the works of sintering. Finally, MSC to predict the densification behavior is constructed. Effects of particle sizes are analyzed and discussed using MSC.

As explained in Section III, dilatometry experiments start an identical heating rate $(10 \mathrm{~K} / \mathrm{min})$ for all samples as the first step, because all samples are thermally debound to $1173 \mathrm{~K}\left(900{ }^{\circ} \mathrm{C}\right)$. In this range, all samples are thermally expanded by heat. In the second step, dilatometry experiments for each SS powder of different mean particle sizes are carried out with three different heating rates $(3,6$, and $10 \mathrm{~K} / \mathrm{min})$.

Figures 4(a) through (c) show the shrinkage behaviors for STS $316 \mathrm{~L}$ as a function of temperature for PF-3F (Figure 4(a)), PF-5F (Figure 4(b)), and PF-15F (Figure 4(c)), respectively. Generally, the slope of the shrinkage curve increases as the heating rate decreases during sintering from $1173 \mathrm{~K}$ to $1623 \mathrm{~K}\left(900{ }^{\circ} \mathrm{C}\right.$ to $\left.1350{ }^{\circ} \mathrm{C}\right)$. The shrinkage curves during the initial heating stage (from $303 \mathrm{~K}$ to $1173 \mathrm{~K}\left(30{ }^{\circ} \mathrm{C}\right.$ to $\left.900{ }^{\circ} \mathrm{C}\right)$ ) and the cooling stage $\left[1623 \mathrm{~K}\right.$ to $303 \mathrm{~K}\left(1350{ }^{\circ} \mathrm{C}\right.$ to $\left.\left.30{ }^{\circ} \mathrm{C}\right)\right]$ have nearly identical slope. Through this initial observation, the initial temperature at which sintering starts was

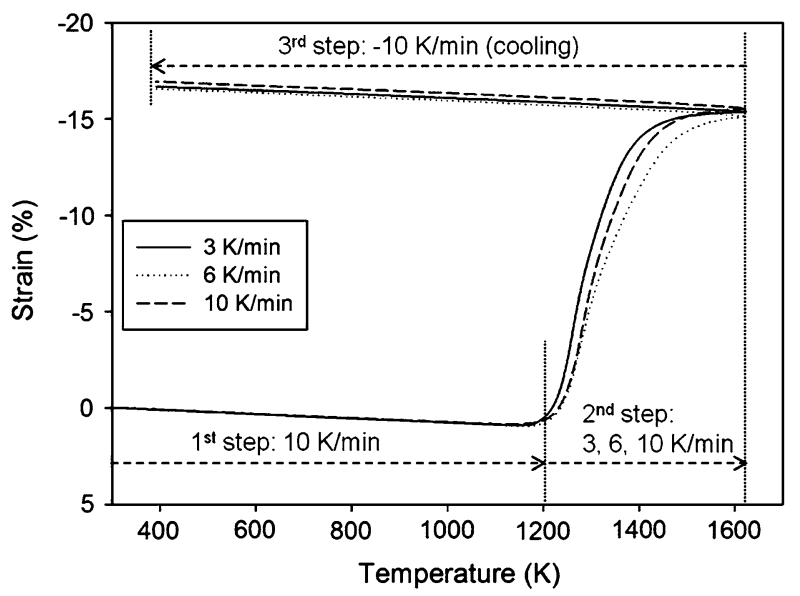

(a)

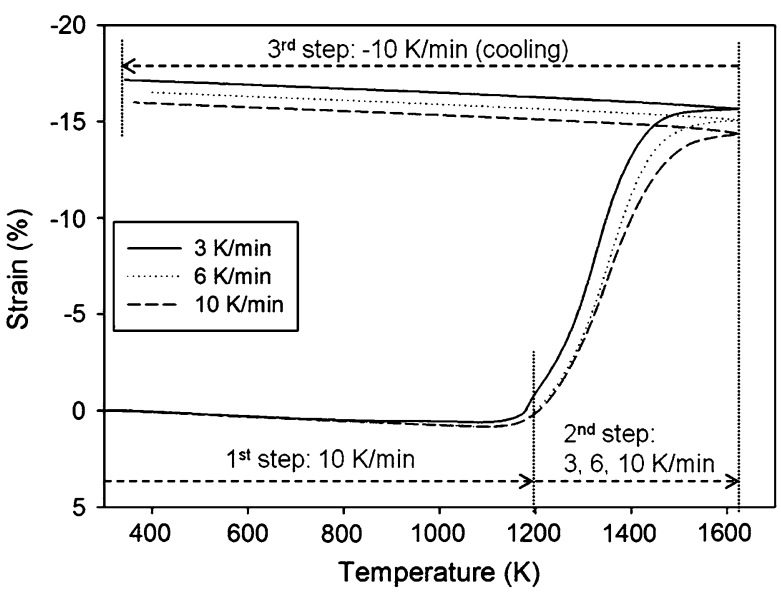

(b)

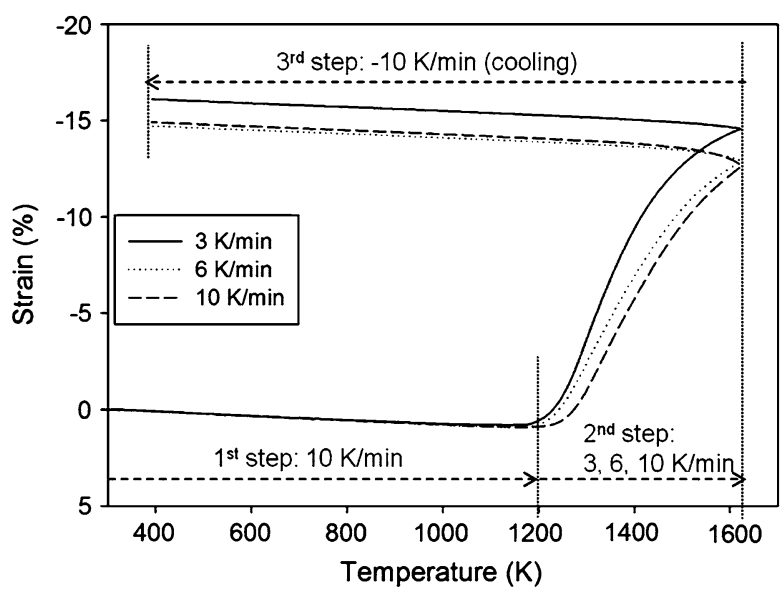

(c)

Fig. 4-Plots of shrinkage for STS316L: (a) PF-3F, (b) PF-5F, and (c) PF-15F. 
Table IV. Thermal Expansion Coefficients with Particle Size for STS316L $\left(10^{-5} \mathrm{~K}^{-1}\right)$

\begin{tabular}{lcccc}
\hline & \multicolumn{3}{c}{ Heating Rate } \\
\cline { 2 - 5 } Powder & $3 \mathrm{~K} / \mathrm{min}$ & $6 \mathrm{~K} / \mathrm{min}$ & $10 \mathrm{~K} / \mathrm{min}$ & 1.002 \\
$\mathrm{PF}-3 \mathrm{~F}(2.97 \mu \mathrm{m})$ & 0.996 & 1.024 & 1.037 & 1.007 \\
$\mathrm{PF}-5 \mathrm{~F}(4.16 \mu \mathrm{m})$ & 1.051 & 1.043 & 1.031 & 1.043 \\
$\mathrm{PF}-15 \mathrm{~F}(8.04 \mu \mathrm{m})$ & 1.011 & 1.009 & 1.017 \\
\hline
\end{tabular}

determined to calculate apparent activation energies. There is no change in the dimension of samples during thermal debinding.

According to the MSC, the extent of the densification has to be identical, regardless of heating rates. Strictly speaking, the heating rate is involved with densification behaviors, because the heating rate influences both the kinetics of shrinkage and microstructures but not the final density of sintered compacts. ${ }^{[23,24]}$ The MSC does not consider the effects of heating rates.

In view of percentages of shrinkages, the samples of smaller particle size have larger shrinkage, i.e., the percentages of shrinkages for PF-3F, PF-5F, and PF$15 \mathrm{~F}$ are about $17,16.5$, and $15.5 \mathrm{pct}$, respectively. These shrinkages confirm those of other research. ${ }^{[25]}$ Equation [12] shows that the shrinkage can be used to explain the relative density.

The thermal expansion coefficients are obtained from the dilatometry data in the cooling step (Figure 4). The thermal expansion coefficients are calculated by linear fitting of the relationship between the strain (i.e., shrinkage) and the temperature, as shown in Table IV. The average value for three different heating rates is chosen as an approximated value of the apparent thermal expansion coefficient, which is notated as $\alpha_{m}$ in Section IV for each particle size. The approximated values of these thermal expansion coefficients are similar to those reported previously. ${ }^{[10]}$ These thermal expansion coefficients are used to compensate the effects of thermal expansion during sintering (Section IV). The strain of the debound samples during sintering is obtained by considering the effects of thermal expansion, since most metals are expanded by heat.

The apparent activation energy is the minimum energy that is required for sinter bonding. The lower apparent activation energy enables easier sinter bonding, leading to the improved densification.

The apparent activation energy is affected by many factors such as particle sizes, grain sizes, and sintering temperatures. Many methods to obtain the apparent activation energy were proposed in the past. Given a value of the apparent activation energy $Q$, a value of mean residual calculated by Eq. [8] is determined. Therefore, the best estimator of the apparent activation energy can be determined from the plot of the mean residuals against the values of $Q$, which minimizes the deviation, i.e., the mean residual.

STS316L does not have the phase changes and has a single apparent activation energy during the sintering from $1173 \mathrm{~K}$ to $1623 \mathrm{~K}\left(900{ }^{\circ} \mathrm{C}\right.$ to $\left.1350{ }^{\circ} \mathrm{C}\right)$. For the materials with phase changes, multiple apparent activation energies should be obtained for corresponding

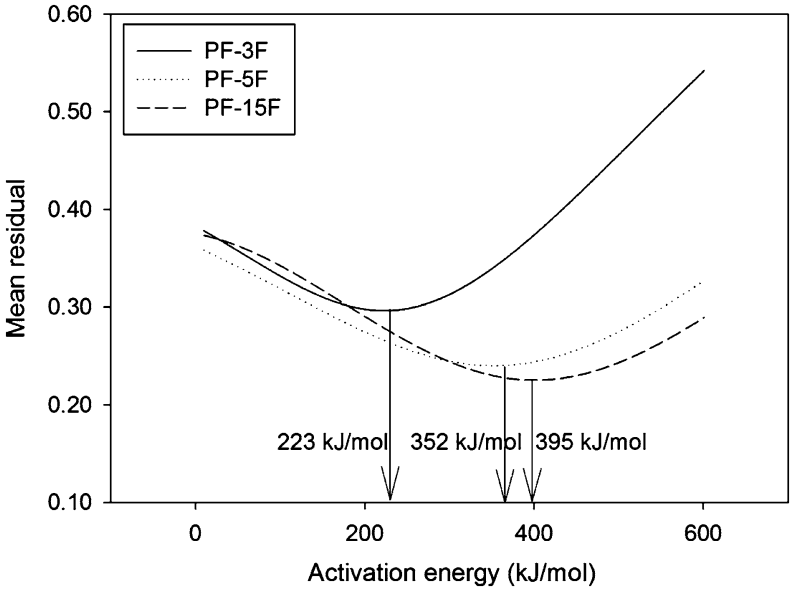

Fig. 5-Approximated apparent activation energies for STS316L: (a) PF-3F, (b) PF-5F, and (c) PF-15F.

Table V. Approximated Apparent Activation Energy with the Minimum Mean Residual

\begin{tabular}{lcc}
\hline Powder & $\begin{array}{c}\text { Mean } \\
\text { Residual }\end{array}$ & $\begin{array}{c}\text { Apparent Activation } \\
\text { Energy }(\mathrm{kJ} / \mathrm{mol})\end{array}$ \\
\hline PF-3F $(2.97 \mu \mathrm{m})$ & 0.296 & 223 \\
PF-5F $(4.16 \mu \mathrm{m})$ & 0.240 & 352 \\
PF-15F $(8.04 \mu \mathrm{m})$ & 0.223 & 395 \\
\hline
\end{tabular}

phases, which are associated with different diffusivities. Blaine et $a l .{ }^{[10]}$ obtained three distinct apparent activation energies corresponding to each phase for $17-4 \mathrm{PH}$ stainless steel.

Figure 5 shows the mean residual as a function of the apparent activation energy for each particle size. The apparent activation energy, which minimizes the mean residual, is determined from these results. Table $\mathrm{V}$ summarizes the best estimators of the apparent activation energy for each particle size.

The results show that the apparent activation energy is significantly affected by particle size in such a way that the apparent activation energy increases along with the particle size. From a physical viewpoint, the contact area among particles will increase as the particle size decreases for a given volume. These larger contact areas lead to better diffusion among particles. Therefore, the powder sample of a smaller particle size will require lower activation energy for sintering. The results imply that the interactions between a pair of particles are enhanced by decreasing the particle size. 


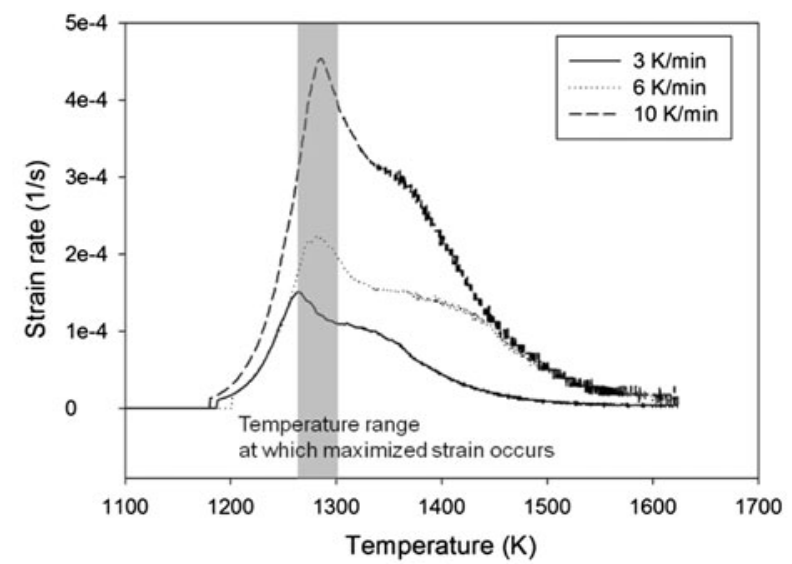

(a)

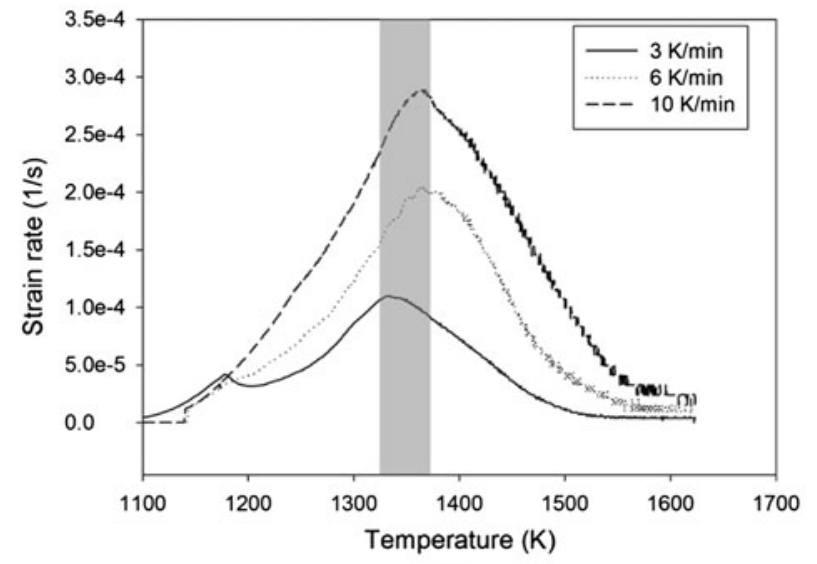

(b)

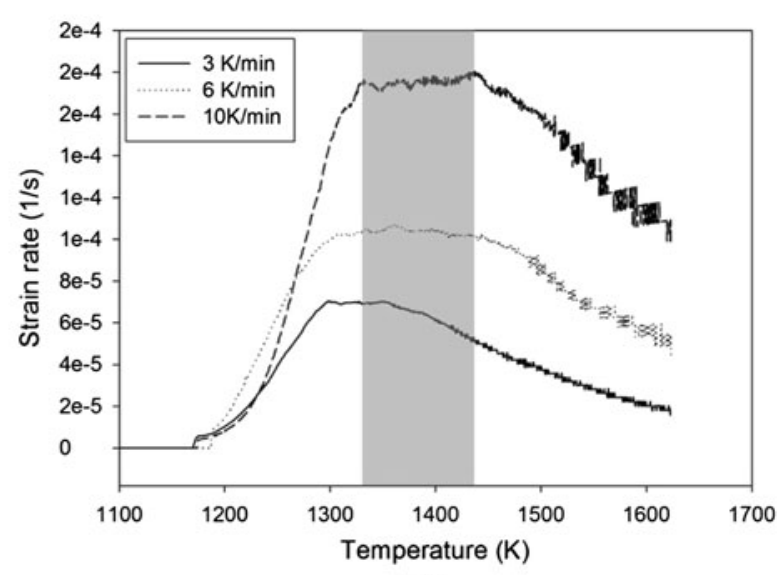

(c)

Fig. 6-Plots of strain rate for STS316L: (a) PF-3F, (b) PF-5F, and (c) PF-15F.

For the verification purpose, the apparent activation energy obtained in this study was compared to Liu et al. ${ }^{[25]}$ which obtained the apparent activation energy for STS316L using samples (mean particle size of $11 \mu \mathrm{m}$ ) of initial relative densities similar to those of this study $\left(\rho_{0} \approx 0.55\right)$. They obtained apparent activation energies of 351.46 to $256.85 \mathrm{~kJ} / \mathrm{mol}$ for the relative densities of 0.6 to 0.8 . The previous works also validate the apparent activation energies that are calculated in this study. Finally, it is found that the larger particle sizes lead to the higher apparent activation energy.

Figure 6 shows that the strain rate is zero up to $1173 \mathrm{~K}\left(900{ }^{\circ} \mathrm{C}\right)$ during the thermal debinding, where the binders in samples are removed and the powders are presintered. In the next temperature interval between $1173 \mathrm{~K}$ and $1623 \mathrm{~K}\left(900{ }^{\circ} \mathrm{C}\right.$ and $\left.1350{ }^{\circ} \mathrm{C}\right)$, particles in samples are bonded into a coherent solid mass. For the temperature interval between $1173 \mathrm{~K}$ and $1623 \mathrm{~K}$ $\left(900{ }^{\circ} \mathrm{C}\right.$ and $1350{ }^{\circ} \mathrm{C}$ ), the temperatures for the maximum strain rates increase slightly as the heating rate increases.

Figure 6 shows that the densification initiates at about $1173 \mathrm{~K}\left(900{ }^{\circ} \mathrm{C}\right)$, confirming the results in Figure 4, and continues to about $1623 \mathrm{~K}\left(1350^{\circ} \mathrm{C}\right)$. The method to approximate the apparent activation energy in this study uses the concept of work of sintering, which is a function of temperature. Therefore, once the temperature range for the work of sintering is determined, the apparent activation energy can be calculated.

In addition, the temperatures for the maximum strain rates increase as the particle size increases (the shaded intervals of Figure 6). The overall magnitude of strain rates tends to increase as the particle size decreases. From this observation, it is concluded that powders of smaller particle sizes have narrower interparticle spaces and promote the densification at lower temperature. Okubo et al. ${ }^{[20]}$ investigated the densities of STS316L samples, which were sintered at different temperatures. They showed that finer powders reached full density at lower sintering temperature, compared with coarse powders. As previously shown by Eq. [12], the change of length during sintering is closely linked to sintering density; thus, the densification for finer powders is achieved at relatively lower temperature.

The MSC explains the relationship of the density and the work of sintering, and it is best described by a sigmoid function when the values of the densification parameter are plotted against the logarithm values of the work of sintering. A sigmoid function is determined by choosing two constant parameters, $a$ and $b$, which are 


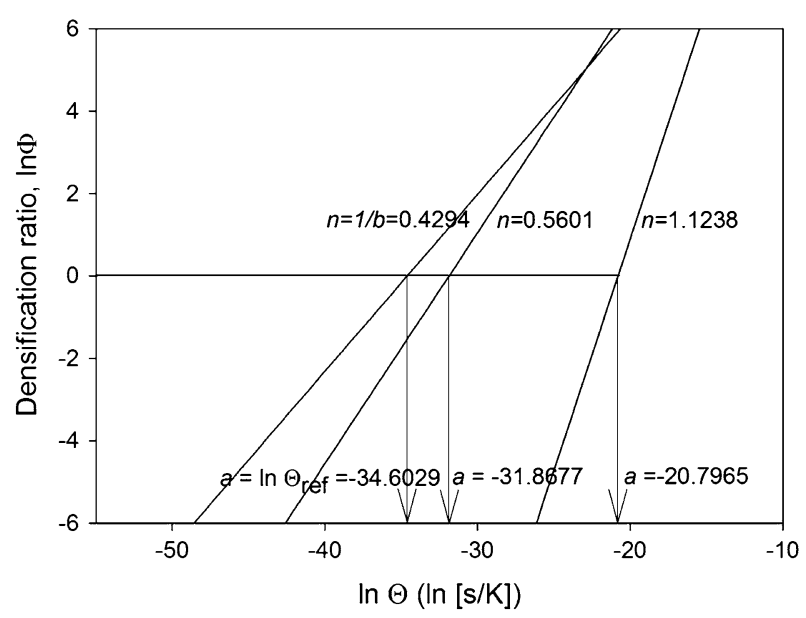

Fig. 7-Linearized forms of MSC for STS316L.

Table VI. Constant Parameters from Sigmoid Curve for Each Particle Size

\begin{tabular}{lccc}
\hline Powder & $a(\ln [\mathrm{s} / \mathrm{K}])$ & $b$ & $R^{2}$ \\
\hline PF-3F $(2.97 \mu \mathrm{m})$ & -20.7965 & 0.8897 & 0.9797 \\
PF-5F $(4.16 \mu \mathrm{m})$ & -31.8677 & 1.7854 & 0.9960 \\
PF-15F $(8.04 \mu \mathrm{m})$ & -34.6029 & 2.3289 & 0.9962 \\
\hline
\end{tabular}

explained in Section II-B. These two constant parameters can be obtained from the linearized form of MSC on the log-log plot between the work of sintering and the densification ratio, $\Phi$.

The linearized form of the MSC for each particle size is plotted in Figure 7. Blaine et al. ${ }^{[15]}$ defines the densification parameter $\Psi$ and the densification ratio $\Phi$ as follows:

$$
\Phi \equiv \frac{\rho-\rho_{0}}{1-\rho_{0}}=\left(\frac{\Theta}{\Theta_{\mathrm{ref}}}\right)^{n}
$$

and

$$
\psi \equiv \frac{\rho-\rho_{0}}{1-\rho_{0}}=\frac{1}{1+\exp \left[-\frac{\ln \Theta-a}{b}\right]}
$$

The constant parameters of a sigmoid function, $a$ and $b$, are obtained by linear fitting to the experimental data. As previously mentioned in Section II-B, constant parameters $a$ and $b$ are defined by $a \equiv \ln \Theta_{\text {ref }}$ and $b=$ $1 / n$, respectively. $\Theta_{\text {ref }}$ is the work of sintering at the midway point through the densification, i.e., $\rho=\left(\rho_{0}+\right.$ $1) / 2$, and $n$ is a power law exponent. In the linearized form of the MSC (Figure 7), the slope is the power law exponent, $n$, which indicates how fast the densification occurs. The logarithm value of work of sintering at the density of $\rho=\left(\rho_{0}+1\right) / 2$, i.e., $\Phi=1$, is $a$, which represents how much densification progresses until then.

Two constant parameters of the sigmoid function, $a$ and $b$, are summarized in Table VI. It is shown that particles of smaller sizes have a larger value of $a$ than particles of larger sizes. This finding indicates that the

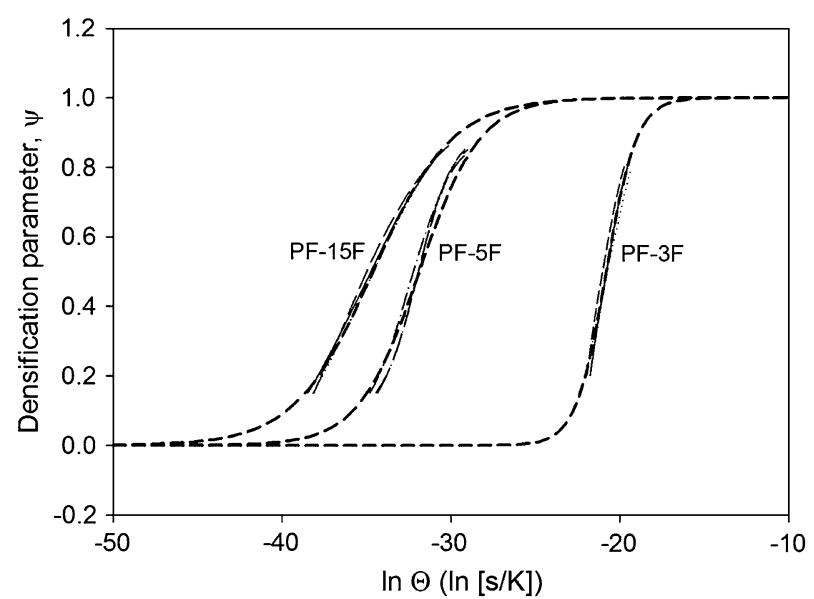

Fig. 8-MSC with sigmoid model for STS316L their consolidated plot.

sintering densification is promoted by decreasing the particle sizes.

The value $n=1 / b$ represents the slope of the linearized form of MSC and, thus, is also related to the rate of sintering densification. The results show that the slope increases as the particle size decreases, which indicates that the sintering densification is enhanced as the particle size decreases.

The MSC originally describes the relationship between the work of sintering and the relative density. Since the densification parameter is a function of the relative density, it is reasonable to express the MSC as the relationship between the work of sintering and the densification parameter for simplicity.

The strain for each particle size can be expressed by an alternative parameter, i.e., the densification parameter $(\psi)$, suggested by Blaine et al. ${ }^{[15]}$ The densification parameter explains the degree of densification using the unit value range from 0 (initial relative density) to 1 (theoretical density). Therefore, it is straightforward to understand the densification behavior with the theoretical density of the material under consideration through the densification parameter. In addition, the densification parameter explains densification behaviors against temperatures. Particles of larger sizes take longer to achieve full density. Figure 8 shows the densification behaviors along with the MSC for each particle size through the densification parameter $(\psi)$. The figure illustrates three curves for experimental data of three different particle sizes and an MSC that consolidates the experimental data of three different particle sizes. Regardless of the heating profiles, the MSC in the form of the sigmoid function predicts well, and it is determined that the densification improves as particle sizes get smaller. Since the slope of the linearized form of MSC indicates the rate of densification, the smaller particle sizes lead to the faster densification.

The smaller particle sizes result in more densification. Since the apparent activation energy of concern in this study is considered as the minimum level of energy by which the sinter bonding occurs, the powders of smaller particle sizes have lower apparent activation energy. 

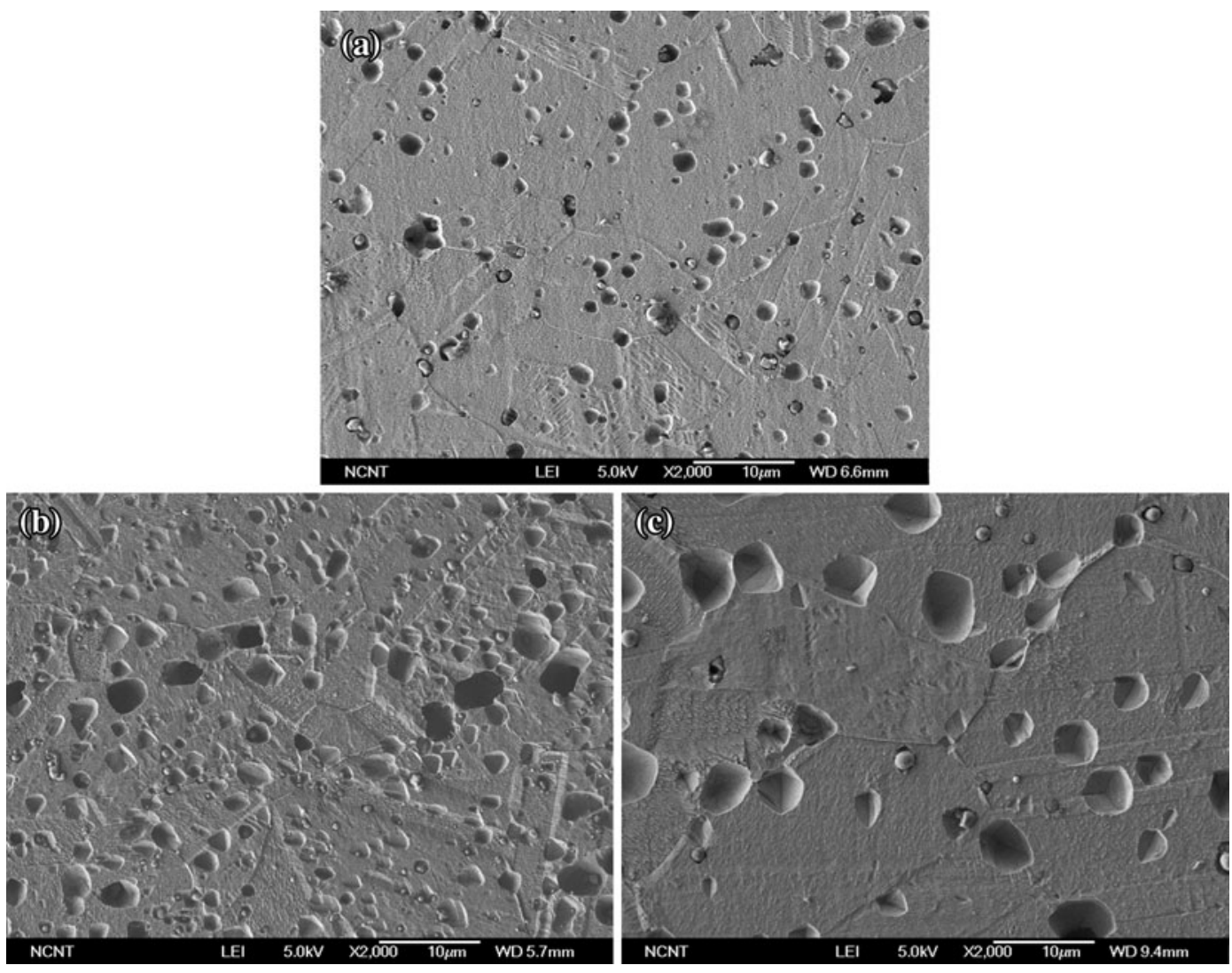

Fig. 9- Comparison of the microstructures for STS316L: (a) PF-3F, (b) PF-5F, and (c) PF-15F. The corresponding heating profile in use is "Heating Profile 2" in Fig. 3.

Larger particle sizes require higher temperatures because of the work of sintering, which is a function of the apparent activation energy and temperature, as shown in Eq. [7].

In Figure 8, as the particle sizes grow larger, the MSCs move to the leftmost ranges of the lower work of sintering. While the samples of smaller particle sizes, i.e., the particle sizes of $2.97 \mu \mathrm{m}$, reach full density at around $-18 \ln (\mathrm{s} / \mathrm{K})$, the samples' larger particle sizes $(4.16$ and $8.04 \mu \mathrm{m})$ reach full density at -26 and -28 $\ln (\mathrm{s} / \mathrm{K})$. The larger particles have smaller contact areas among them for diffusion bonding, which was confirmed and verified through the observation of microstructures, since the density is related to the porosity. The larger particles lead to more pores in the samples. It is apparent that the sintering response of stainless steels is significantly subject to particle sizes.

Finally, since the MSCs are expressed best by the sigmoid function, two constant parameters, $a$ and $b$, with the apparent activation energy obtained by the minimization of the mean residual, can be used to predict the densification behavior for various sintering conditions. The sigmoid functions for the MSC of powders used in this study are illustrated in Figure 8.

The sintered samples were characterized by their density and dimensional changes. Subsequently, the samples were cut and mounted in mounting resin, which holds the small sample. The density was determined by the Archimedes water immersion method. The mounted
Table VII. Relative Densities for Sintered Samples

\begin{tabular}{lccc}
\hline & $3 \mathrm{~K} / \mathrm{min}$ & $6 \mathrm{~K} / \mathrm{min}$ & $10 \mathrm{~K} / \mathrm{min}$ \\
\hline $\mathrm{PF}-3 \mathrm{~F}$ & 0.983 & 0.958 & 0.948 \\
PF-5F & 0.958 & 0.956 & 0.945 \\
PF-15F & 0.954 & 0.953 & 0.947 \\
\hline
\end{tabular}

samples were plane polished to expose the internal microstructure of the sintered samples. The task of polishing was carried out by MD-Dac plate, using suspensions that are monocrystalline diamond suspension (which contains diamond particles of 9,3 , and $1 \mu \mathrm{m}$ in diameter) and single crystalline diamond suspension containing diamond particles of $0.25 \mu \mathrm{m}$ in diameter. Etching was performed with a 2 pct $\mathrm{HF}, 9$ pet $\mathrm{HNO}_{3}$, 9 pct $\mathrm{HCL}$, and 80 pct $\mathrm{H}_{2} \mathrm{O}$ solution for 3 minutes. The SEM pictures for microstructures of STS316L are given in Figure 9. As the sizes of particles grow larger, the microstructure shows larger pores and irregular shape. The irregular shape of morphology for STS316L is formed along the grain boundaries or the grains. As previously mentioned, the pores are formed by trapped $\mathrm{H}_{2} \mathrm{O}$ by chemical reaction between oxygen and hydrogen. The microstructure confirmed and verified that larger particles result in larger grains and higher porosities. The amount of volume occupied by pores is closely related with the final relative density. As the 
sintered samples have more pores, the relative density decreases. The relative densities for sintered samples are reported in Table VII.

\section{CONCLUSIONS}

In this study, the MSCs for each particle size are constructed by conducting three different experiments, which are different heating profiles. As each of the MSCs represents the sintering behaviors, it is possible to analyze the characteristic of sintering behavior using MSCs for each particle size. After analyzing the sintering behavior in terms of the apparent activation energy, strain rate, constant parameters of linearized form, and MSC, the results are confirmed and verified through microstructure analysis. The effects of the particle size on the sintering behavior are summarized as follows.

The apparent activation energy is significantly affected by particle size in such a way that it increases along with the particle size. The samples of a smaller particle size require lower apparent activation energy, since the interactions between a pair of particles are enhanced by decreasing the particle size.

1. The temperature at which the strain rate reaches maximum value decreases as the particle size decreases. The samples of smaller particle sizes have narrower interparticle space and, thus, promote the densification at lower temperature.

2. From constant parameters, $a$ and $b$, of linearized forms, a quantity at the midway point through the densification and a speed of densification are obtained by linear fitting to the experimental data. The smaller particle size has the relatively higher value of $a$ than larger particle size. The slope, $n$, of linearized form increases as the particle size decreases, indicating that the sintering densification is promoted by decreasing the particle sizes.

\section{ACKNOWLEDGMENTS}

This research was supported by the World Class University (WCU) program through the National Research Foundation of Korea funded by the Ministry of Education, Science and Technology (Grant No. R31-30005) and a National Research Foundation of Korea (NRF) grant funded by the Korean government (MEST) (Grant No. 2012-0009249).

\section{REFERENCES}

1. R.M. German and A. Bose: Injection Molding of Metals and Ceramics, Princeton, NJ: Metal Powder Industries Federation, 1997.

2. F.V. Lenel: Powder Metallurgy Principles and Applications, Princeton, NJ: Metal Powder Industries Federation, 1980.

3. P. Garg, S.J. Park, and R.M. German: Int. J. Refract. Met. H, 2007, vol. 25 (1), pp. 16-24.

4. L. Liu, N.H. Loh, B.Y. Tay, and S.B. Tor: Powder Technol., 2011, vol. 206 (3), pp. 246-51.

5. G.N. Hassold and I. Chen: J. Am. Ceram. Soc., 1990, vol. 73 (10), pp. 2857-64.

6. R. Coble: J. Appl. Phys., 1961, vol. 32 (5), pp. 787-92.

7. C. Reid: Powder Technol., 1994, vol. 81 (3), pp. 287-91.

8. H. Su and D.L. Johnson: J. Am. Ceram. Soc., 1996, vol. 79 (12), pp. 3211-17.

9. I.M. Robertson and G.B. Schaffer: Metall. Mater. Trans. A, 2009, vol. 40A, pp. 1968-79.

10. D.C. Blaine, S.J. Park, P. Suri, and R.M. German: Metall. Mater. Trans. A, 2006, vol. 37A, pp. 2827-35.

11. S.J. Park, J.M. Martin, J.F. Guo, J.L. Johnson, and R.M. German: Metall. Mater. Trans. A, 2006, vol. 37A, pp. 2837-48.

12. D.C. Blaine, J.D. Gurosik, S.J. Park, D.F. Heaney, and R.M. German: Metall. Mater. Trans. A, 2006, vol. 37A, pp. 715-20.

13. S.J. Park and R.M. German: IJMSI, 2007, vol. 1 (1), pp. 128-47.

14. S.J. Park, S.H. Chung, J.M. Martin, J.L. Johnson, and R.M. German: Metall. Mater. Trans. A, 2008, vol. 39A, pp. 2941-48.

15. D.C. Blaine, S.J. Park, and R.M. German: J. Am. Ceram. Soc., 2009, vol. 92 (7), pp. 1403-09.

16. S.J. Park, P. Suri, E. Olevsky, and R.M. German: J. Am. Ceram. Soc., 2009, vol. 92 (7), pp. 1410-13.

17. R. Bollina, S.J. Park, and R.M. German: Powder Metall., 2010, vol. 53 (1), pp. 20-26.

18. D. Blaine, S. Park, and R. German: Master Sintering Curve for a Two-Phase Material, Sintering '05.

19. J.D. Hansen, R.P. Rusin, M.H. Teng, and D.L. Johnson: J. Am. Ceram. Soc., 1992, vol. 75 (5), pp. 1129-35.

20. K. Okubo, S. Tanaka, and H. Ito: Microsyst. Technol., 2010, vol. 16 (12), pp. 2037-41.

21. L. Liu, N.H. Loh, B.Y. Tay, S.B. Tor, H.Q. Yin, and X.H. Qu: Appl. Phys. A-Mater., 2011, vol. 103 (4), pp. 1145-51.

22. J. Wang and R. Raj: J. Am. Ceram. Soc., 2005, vol. 73 (5), pp. $1172-75$.

23. T. Pieczonka, J. Kazior, A. Tiziani, and A. Molinari: J. Mater. Process. Technol., 1997, vol. 64 (1-3), pp. 327-34.

24. J. Ryu, J.J. Choi, and H.E. Kim: J. Am. Ceram. Soc., 2001, vol. 84 (4), pp. 902-04.

25. Z.Y. Liu, N.H. Loh, K.A. Khor, and S.B. Tor: Scripta Mater., 2001, vol. 44 (7), pp. 1131-37. 